\section{Vesico-vaginal fistula: A clinical study}

S.V. Krishna Reddy, ${ }^{1}$

Ahammad Basha Shaik ${ }^{2}$

${ }^{1}$ Department of Urology, Narayana

Medical College \& Hospital;

${ }^{2}$ Department of Community Medicine,

Narayana Medical College \& Hospital, Nellore, Andhra Pradesh, India

\begin{abstract}
In a retrospective study, the records of 34 women with a mean \pm SD age of the patients was $36.62 \pm 9.02$ years were assessed; $32.35 \%$ of the vesico-vaginal Fistula (VVF) occurred after abdominal hysterectomy, $11.77 \%$ after Caesarean section, $32.35 \%$ after difficult vaginal delivery and $23.53 \%$ after instrumental delivery. Six women (17.64\%) had a previous failed repair. The duration (mean $\pm \mathrm{SD}$ ) of the VVF was $5.68 \pm 1.59$ months. Of the 34 VVF patients, 20 (58.82\%) were Mid-Vaginal VVF, 8 (23.53\%) were Circumferential VVF, $3(8.82 \%)$ were Juxta cervical VVF and 3 (8.82\%) were Juxta Urethral VVF. An abdominal approach was used in 21 cases $(61.76 \%)$, vaginal repair was contemplated in $8(23.53 \%)$ cases and Laparoscopic in 5 (14.71\%). At a mean duration of follow-up was $33.06 \pm 1.72$ months and the VVF was cured in $28(82.4 \%)$ patients. Only previous intervention and timing of surgery $(\mathrm{P}=0.004)$ and surgical approach $(\mathrm{P}=0.02)$ maintained significance in our study. An abdominal/ Laparoscopic approach seems to give superior results. Previous failed repair had a significant negative effect on success. A late repair $(\geq 6$ months) is associated with higher success rates.
\end{abstract}

\section{Introduction}

Vesico-vaginal Fistula (VVF) is an abnormal communication between the bladder and vagina and represents the most frequent type of female urinary fistula. Women with VVF a continuous leakage of urine from the vagina, usually with absence of urethral voiding, resulting in strong negative impact on their quality of life. The existence of VVF is believed to have been known to the physicians of ancient Egypt, present in mummies before 2,000 years BC. However, not until 950 AD did Avicenna identified that difficult labor at a young age resulted in the formation of a vesico-vasical communication. It can result from obstetric trauma, surgery, infection, malignancy or congenital anomalies. ${ }^{1}$ Prolonged, obstructed labor is the leading cause of VVF. This, however, is an uncommon occurrence in the developed world, largely due to the availability of advanced obstetric practice. ${ }^{2,3}$ In contrast, it usually develops as a complication of pelvic or gynaecological operations like hysterectomy in western countries. Obstructed labor, most commonly occurring when a baby's head becomes lodged in the mother's pelvis leading to hypoxia resulting from prolonged pressure on the soft tissues of the vagina, bladder base, and urethra and pressure necrosis leading to fistula formation. ${ }^{4-6} \mathrm{VVF}$ following hysterectomy is most likely to arise from an unrecognized bladder injury at the time of surgery. Inadvertently placed suture between the bladder and vaginal wall may also contribute to the formation of VVF. There are two main types of VVFs: simple and complex fistulas. Large $(\geq 0.5 \mathrm{~cm})$, multiple, chronic or developing after radiotherapy fistulas are classified as complex ones. ${ }^{7,8}$

In 1852, James Marion Sims considered the father of fistula repair reported a successful repair of VVF in female slaves. In a period where women were generally left untreated, it was the first report of a successful repair. ${ }^{9}$ The new classification was proposed by Judith (2004) ${ }^{10}$ which divides genitourinary fistulae into four main types, depending on the distance of the distal edge of the fistula from the external urinary meatus. O'Conor et al. (1980) ${ }^{10-28}$ popularized the Suprapubic Intraperitoneal or Extraperitoneal approach. The abdominal approach can be performed using a transvesical (fistula excision) or an extra-vesical (bivalve technique) approach. In reality both procedures involve the opening of the bladder. Trendelenberg $(1888)^{11}$ described trans abdominal, trans-vesical repair which has become the standard treatment for difficult VVF. Trans vaginal repairs were introduced in an effort to decrease operative morbidity. ${ }^{12}$ Success rates have been shown to be equivalent to those for trans abdominal repair. ${ }^{13}$ The vaginal flap technique is the most commonly used method of repair. ${ }^{14}$ Still, Raz et al. (1993) $)^{15}$ achieved a good success rate $(82 \%)$ performing vaginal repair in complex fistulas, and Wang et al. achieved a $94 \%$ success rate with a vaginal approach to the treatment of high lying fistulas. ${ }^{16}$ Laparoscopic repair of VVFs was first reported by Nezhat et al. (1994). ${ }^{17}$ Laparoscopic or robotic-assisted repair of fistulae located above the trigone is gaining increasing popularity because these procedures have a potential to decrease the morbidity of the open abdominal approach as reported by Nabi et al. (2001). ${ }^{18}$
Correspondence: S.V. Krishna Reddy, Department of Urology, Narayana Medical College \& Hospital, Nellore-524003, Andhra Pradesh, India.

Tel: +918612321828 - Fax: +918612300068. E-mail: krishnareddysv@narayanagroup.com

Key words: Fistula; Hysterectomy; Iatrogenic; Obstructive labor; Vesico-vaginal.

Conflict of interest: the authors declare no potential conflict of interest.

Funding: none.

Received for publication: 11 September 2017 Revision received: 30 December 2018.

Accepted for publication: 30 December 2018.

This work is licensed under a Creative Commons Attribution NonCommercial 4.0 License (CC BY-NC 4.0).

(C) Copyright S.V.K. Reddy and A.B. Shaik, 2019 Licensee PAGEPress, Italy

Urogynaecologia 2019; 31:203

doi:10.4081/uij.2019.203

\section{Materials and Methods}

This case series study included 42 and only 34 patients with VVF, who had complete records from January 2011 to December 2016, and who had been treated by more than one surgeon who had done at least 10 cases each. Our study was approved by our institutional ethics committee. Written informed consent was taken from all patients for photographing, recording and also its use for scientific and medical education purposes. On admission detailed history was taken and at the time of diagnosis all patients had a local examination, basal biochemical profile (complete blood count, serum creatinine and urine analysis). A routine ultrasonography of kidney, ureters, and bladder region was done in all. Imaging studies included Intravenous urogram, Magnetic resonance imaging when felt necessary and appropriate. An ascending cystogram with anteroposterior and lateral views was taken. The three-gauze test with methylene blue instilled in the bladder to detect fistulae undetected on the cystogram was also used. Eight patients with doubtful neuropathic bladder dysfunction and urethral sphincteric incompetency, female circumcision and the practice of harmful traditional medical practices such as anterior vaginal wall incisions and the insertion of caustic substances into the vagina with the intent to treat a gynecologic condition and complex malignant fistula 
were excluded from the study.

Cystoscopy was done to identify the fistula and note its size, position, and surroundings. At the same instance vaginoscopy was done to observe the end of the fistula. In the evaluation of the patient records, the duration of the VVF, the cause and any previous repair were all documented. The duration of urethral catheter drainage and the use of bilateral ureteric catheters were also recorded. The site and the number of fistulous openings was also recorded; the VVF was considered 'low' when the fistulous opening was below the inter-ureteric ridge, 'high' when above this line, and a fistula at the bladder neck was considered as a separate entity. To the performance of the surgical treatment, we recommend a minimum of a 4-6 week's wait from the onset of the fistula. The approach (abdominal or vaginal) was recorded and the use of an interposition flap was checked. In the abdominal approach we used a midline infra-umbilical incision and trans-vesical approach, while in a vaginal approach we identified the fistulous opening using an Auvard weighted vaginal retractor, insertion of a small caliber Foley catheter in the fistulous tract and complete excision of the tract, with a two-layer closure of the bladder and vaginal mucosa. The vaginal repair techniques can be categorized as to those that are modifications of the Latzko procedure or a layered closure with or without a Martius flap. The most frequently used abdominal approaches are the bivalve technique or the fistula excision (Figure 1). Radiated fistulas usually required a more individualized management and complex surgical procedures.

Laparoscopic VVF Repair: The patient is first placed in low lithotomy and cystoscopy is performed to see the site, size, number of fistulas. A 4 port transperitoneal approach is used (a $12 \mathrm{~mm}$ infraumbilical trocar, two additional $10 \mathrm{~mm}$ trocars in the right and left lower quadrants and a $5 \mathrm{~mm}$ suprapubic trocar). The peritoneum over the bladder is incised transversely and the bladder opened vertically down up to the fistula. Stay sutures were placed at bladder edges for exposure. The bladder is separated from the vagina, completely excising the fistula margin and adjacent fibrotic tissue. The bladder and vagina are closed separately with a single layer of full thickness-interrupted 2-0 vicryl sutures. An omental flap or pericolic fat is interposed between the bladder and vaginal suture lines. Discharge data were reviewed and only those patients who were reported continent were considered as a success. We considered the following variables to be important risk factors, and were available for all patients; a history of previous repair, duration of the VVF until treatment ( $<6 v s>6$ months), position of the VVF on pan-endoscopy (high, low, high and low, or low and bladder neck), number of VVF (single $v s$ multiple), and approach of surgery (abdominal, vaginal or lapro( $<14$ days, 14-21 days or $>21$ days) and the adjunctive use of a ureteric catheter. There is no best approach for all patients with VVF. Although factors such as size, location, and need for adjunctive procedures often have an impact on the choice of approach, the most important factor is commonly the experience of the operating surgeon.

\section{Statistical analysis}

The data has been entered into MSExcel and data analysis has been done by using IBM SPSS Version 22.0 (IBM SPSS, Chicago, USA). For continuous variables, the descriptive statistics was calculated. For categorical variables, the data values are represented as number and percentages. To test association between groups, Chi-square test was used. All the P value less than 0.05 are considered statistically significant.

\section{Results}

The median duration of the VVF until treatment was 10.2 months. The mean \pm $\mathrm{SD}$, (range) age of the patients was $36.62 \pm$ $9.02(18-55)$ years respectively; Eleven $(32.35 \%)$ patients had a VVF after an abdominal hysterectomy, $4(11.77 \%)$ after Caesarean section, 11 (32.35\%) after a difscopic), duration of urethral catheterisation

ficult vaginal delivery and $8(23.53 \%)$ after instrumental delivery and were shown in Table 1 and Figure 2. In all, 7 (20.59\%) patients had a previous failed repair of the VVF elsewhere. On pan-endoscopy, 20 (58.82\%) were Mid-Vaginal VVF, 8 $(23.53 \%)$ were Circumfrential VVF, 3 $(8.82 \%)$ were Juxta cervical VVF and 3 $(8.82 \%)$ were Juxta Urethral VVF and were

Table 1. Socio-demographic characteristics of patients with vesico-vaginal fistula.

\begin{tabular}{lcc}
$\begin{array}{l}\text { Variables } \\
\text { (N=34) }\end{array}$ & $\begin{array}{c}\text { Number } \\
(\%)\end{array}$ & Percentage \\
Age (Years) & & \\
$<18$ Years & 8 & 23.53 \\
$\geq 18$ Years & 26 & 76.47 \\
Parity & & \\
I & 11 & 32.35 \\
II-IV & 16 & 47.06 \\
$>$ V & 7 & 20.59 \\
\hline Duration of labor & & \\
1 Day & 8 & 23.53 \\
2-3 Days & 18 & 52.94 \\
$>3$ Days & 8 & 23.53 \\
Place of delivery & & \\
Health Facility & 26 & 76.47 \\
Home & 8 & 23.53 \\
\hline Mode of delivery & & \\
Vaginal Delivery & 11 & 32.35 \\
Instrumental & 8 & 23.53 \\
Cesarean Section & 4 & 11.77 \\
Hysterectomy & 11 & 32.35 \\
Duration of bladder catheter \\
10 Days & 8 & 23.53 \\
14 Days & 18 & 52.94 \\
21 Days & 8 & 23.53 \\
\hline
\end{tabular}

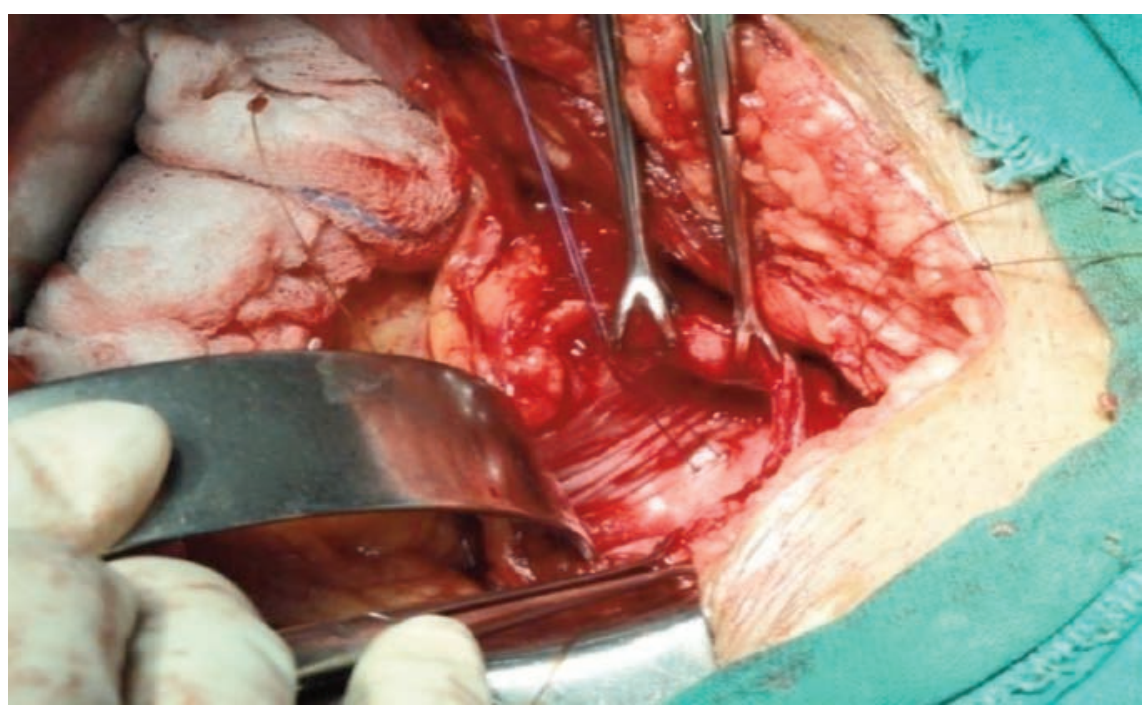

Figure 1. Intra-operative trans-vesical picture showing high supratrigonal vesico-vaginal fistula. 
shown in Table 2 and Figure 3. All VVF but $3(8.82 \%)$ were single. An abdominal approach was used in 21 cases $(61.76 \%)$, with interposition of omental or peritoneal (eight cases) flaps, according to the surgeon's discretion. Vaginal repair was contemplated in $8(23.53 \%)$ cases and Laparoscopic in $5(14.71 \%)$ as shown in Table 2. A urethral catheter was left in situ after the repair for a variable duration, for a median of 14 days (according to the surgeon's rating of the difficulty of surgery). Ureteric catheters, as a method of urinary diversion, were used in $28(82.35 \%)$ of the cases. Again, the only indication for a ureteric catheter was the surgeon's preference. Based on discharge data and subsequent follow-up visits, the initial success rate was $28(82.35 \%)$ patients. Those who were initially failures consisting of 6 $(17.65 \%)$ patients were followed up using the hospital database. One patient was lost to follow-up; another reported continence at 6 months after discharge and a cystogram was taken confirming the disappearance of the VVF. In four patients a second procedure failed, had a subsequent successful repair of the VVF. The mean duration of follow-up is 33 months, where the success rate of surgery was last reported in patients who had a successful first repair. We considered the following variables to be important risk factors, and were available for all patients; a history of previous repair, duration of the VVF until treatment ( $<6$ months $v s>6$ months), Position of the VVF on panendoscopy (high, low, high and low, or low and bladder neck), number of VVF (single vs multiple), and approach of surgery (Laparoscopic, abdominal, vaginal), duration of urethral catheterisation $(<14$ days,
14-21 days or $>21$ days) and the adjunctive use of a ureteric catheter. Table 2 shows the comparison of VVF repair with surgical outcome analysis reveals that primary fistula repair $(89.29 \%)$ had significantly better success rate when compared with previous repair $(10.71 \%)(\mathrm{P}=0.012)$. Regarding the duration, more than six months waiting

Table 2. Comparison of vesico-vaginal fistula (VVF) repair with surgical outcome analysis.

\begin{tabular}{|c|c|c|c|c|}
\hline \multirow[t]{2}{*}{ Variables } & \multicolumn{2}{|c|}{ Surgical outcome } & Total & P \\
\hline & $\begin{array}{l}\text { Success } \\
\text { N }(\%)(n=28)\end{array}$ & $\begin{array}{c}\text { Failure } \\
\text { N (\%) }(n=6)\end{array}$ & $N(\%)(n=34)$ & value \\
\hline
\end{tabular}

\begin{tabular}{lcccc}
$\begin{array}{l}\text { Duration of WF (Months) } \\
<6\end{array}$ & $2(7.14 \%)$ & $4(66.67 \%)$ & $6(17.65 \%)$ & $0.004^{*}$ \\
$>6$ & $26(92.86 \%)$ & $2(33.33 \%)$ & $28(82.35 \%)$ & \\
$\begin{array}{l}\text { Primary vs Secondary } \\
\text { (Goh classification) }\end{array}$ & & & \\
$\quad$ Previous Repair & $3(10.71 \%)$ & $4(66.67 \%)$ & $7(20.59 \%)$ & $0.012^{*}$ \\
$\quad$ Primary Fistula & $25(89.29 \%)$ & $2(33.33 \%)$ & $27(79.41 \%)$ & \\
\hline Type of WF & & & & \\
(anatomic classification) & & & & \\
Mid-Vaginal WF & $17(60.71 \%)$ & $3(50.0 \%)$ & $20(58.82 \%)$ & 0.635 \\
Circumfrential WF & $6(21.43 \%)$ & $2(33.33 \%)$ & $8(23.53 \%)$ & \\
Juxta cervical WF & $2(7.14 \%)$ & $1(16.67 \%)$ & $3(8.82 \%)$ & \\
$\quad$ Juxta Urethral WF & $3(10.71 \%)$ & $0(0.00 \%)$ & $3(8.82 \%)$ & \\
Surgery Approach & & & & \\
Abdominal & $19(67.86 \%)$ & $2(33.33 \%)$ & $21(61.76 \%)$ & $0.020^{*}$ \\
Vaginal & $4(14.29 \%)$ & $4(66.67 \%)$ & $8(23.53 \%)$ & \\
Laparoscopic & $5(17.86 \%)$ & $0(0.00 \%)$ & $5(14.71 \%)$ & \\
\hline
\end{tabular}

${ }^{*} \mathrm{P}<0.05$ - Significant.

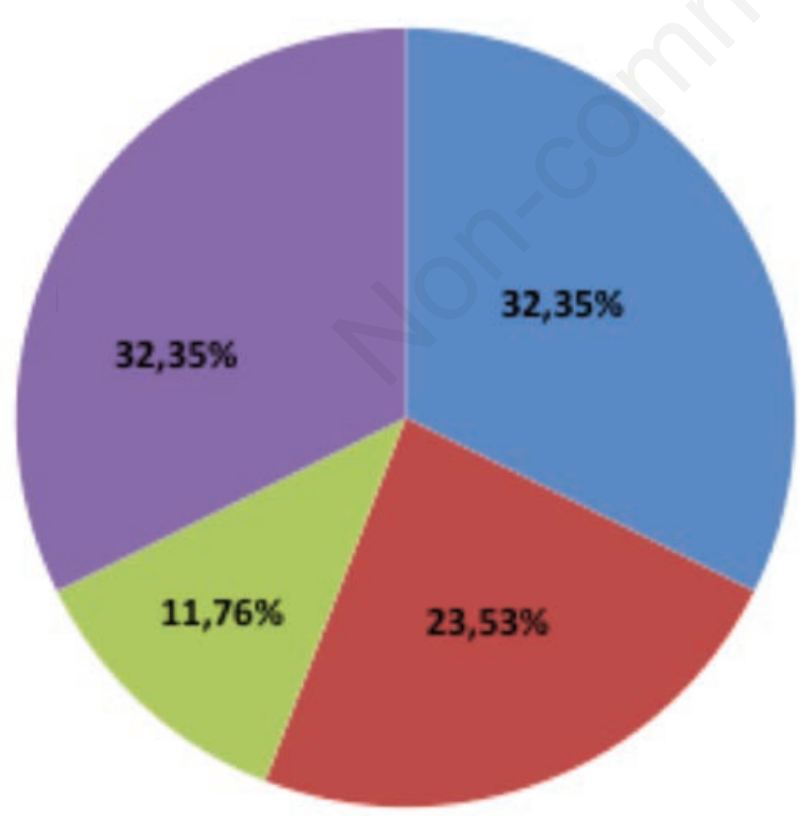

- Vaginal Delivery Cesarean Section
Instrumental

- Hysterectomy

Figure 2. Mode of delivery.

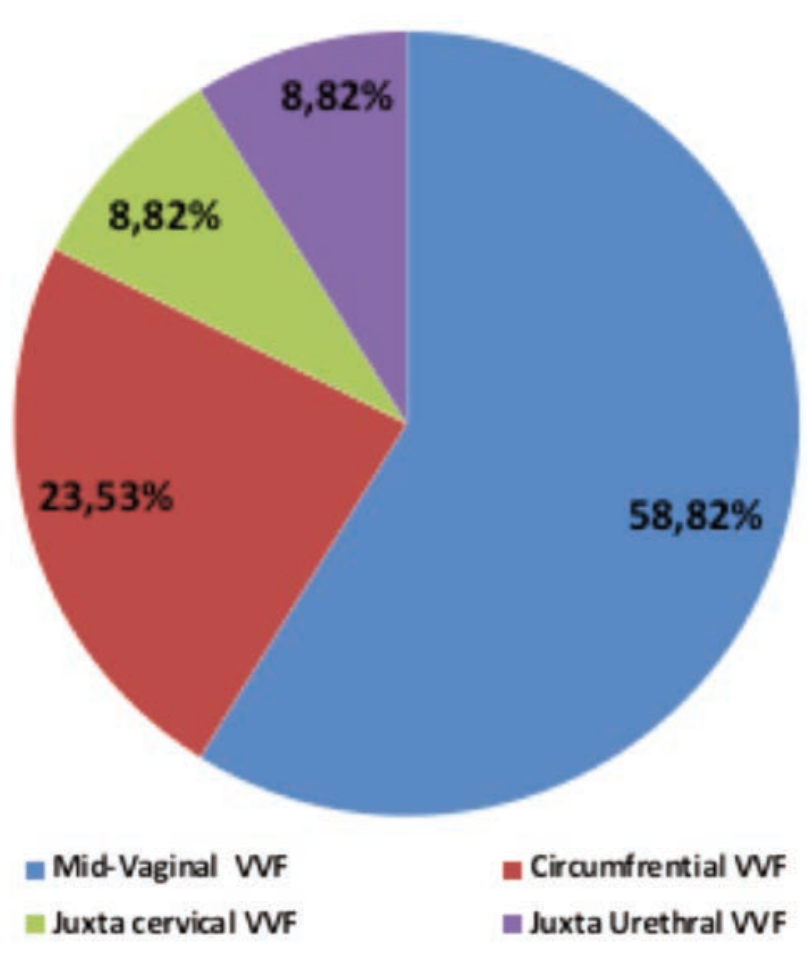

Figure 3. Types of vesico-vaginal fistula (VVF): anatomic classification. 
period had significantly better result $(92.86 \%)$ when compared with repair done before six months $(7.14 \%)(\mathrm{P}=0.004)$. In surgical approach, Abdominal (67.86\%) and laparoscopic repair $(17.86 \%)$ had significantly better outcome than vaginal repair $(14.29 \%)$ of $\mathrm{VVF}(\mathrm{P}=0.02)$.

\section{Discussion}

Regardless of the technique used and the timing of surgery, the principles that underlying VVF repair remains the same. The tissues at the site of the repair should be healthy and a well vascularized interposition flap should be used if required. The first attempt at VVF repair has the highest chance of success, making it imperative that surgery is well planned and performed by a surgeon experienced in fistula repair. VVF repair can be approached trans vaginally, trans abdominally, or in a combined approach if necessary. In their analysis, Wall et al. (2004) ${ }^{19}$ found the leading cause of VVF to be obstetric trauma. In our patients the cure rate was $82.4 \%$ with a median duration of the VVF of 10.2 months. The factors compromising the success of surgical correction of VVF were tissue ischaemia, radiation and recurrence. None of our patients had previous pelvic irradiation, yet $20.59 \%$ of them had one or more previous failed repair. Previous VVF repair was a significant factor affecting the outcome of surgery. However, Eilber et al. $(2003)^{20}$ concluded that the approach chosen for VVF repair should be that with which the surgeon is most comfortable. In the present study, about $75 \%$ patients received repair of VVF via transabdominal approach whereas the rest undergone surgery by vaginal route. The later approach is associated with minimal blood loss, less morbidity, early ambulation and shorter hospital stay. Trans abdominal approach is the preferred approach for repair of larger fistula, fistula lying close to the ureteric orifice and for recurrent or complex fistula. The prime advantage of abdominal route is the availability of omentum which is used as an interposition flap. The overall fistula closure rate varies from center to center which may be affected by fistula characteristics and the experience of the surgeon. In the present study the overall closure rate was $82.4 \%$ and $17.6 \%$ of the patients developed urinary incontinence though their fistula was healed at discharge. This finding is comparable with studies in Africa ${ }^{21,22}$ though there are reports of low fistula closure rate in another study. ${ }^{23}$ Vaginal (or combined abdominal and vaginal) repair were associated with higher failure rates than the abdominal approach. ${ }^{24}$ Possibly this is because abdominal repair is easy to learn, considering that the present patients were managed by several urologists over a long period. ${ }^{25}$ Laparoscopy is an interesting alternative to traditional laparotomy. It offers minimal invasiveness, magnification of the operated area, improved haemostasis, less postoperative pain and faster recovery. ${ }^{26}$ The laparoscopic technique of fistula closure differs in several case reports that have already been published. Similar to our study were $5(14.71 \%)$ as shown in Table 2, Chibber et al. (2005) ${ }^{27}$ prefer traditional cystotomy starting at the dome of the bladder and continuing down to the fistula posteriorly. It is similar to the trans abdominal technique that was originally described by O'Conor (1980). ${ }^{28}$ Such a large cystotomy provides excellent visualization of the site; however, it is more traumatic to the bladder, causes more blood loss and increases the operative time due to the necessity of intracorporeal suturing. Rizvi et al. (2010) ${ }^{29}$ believe that a smaller incision also allows one to perform successful surgery. The advantage of this strategy is a lower risk of probable postoperative bladder irritability. Successful robotic VVF repair was first reported in 2005..$^{30}$ A five-port technique has been described using a vaginal pack to maintain pneumo peritoneum throughout the case. ${ }^{31}$ The successful closure was confirmed by the retention of pneumo peritoneum after the removal of the vaginal pack. Advantages of the robotic technique include three-dimensional visualization, technically simpler intracorporeal knot tying. Every case should be treated by the appropriate surgical approach according to the type of fistula and condition of the vagina. Complications include recurrent fistula formation, ureteric injury or obstruction, vaginal stenosis, reduced bladder capacity and irritative lower urinary tract symptoms. Small recurrent fistulae can be managed conservatively with prolonged catheterization or a second attempt at surgical repair can be made once the tissues have fully recovered. Vaginal stenosis is rare and may require further surgery to make relaxing incisions or to site skin grafts.

\section{Conclusions}

VVFs are among the most distressing complications with social consequences regardless of the etiopathology. The best chance of a successful repair is at the first attempt. However, the role of interposition grafts at both abdominal and vaginal repairs is viewed positively by the respective authors. Adjuvant techniques are needed for complex fistulas. Measures for prevention must include universal education, and improved and accessible medical services.

\section{References}

1. Goodwin W, Scardino P. Vesico-vaginal and ureterovaginal fistulas: a summary of 25 years of experience. J Urol 1980;123:370-4.

2. Evans DH, Madjar S, Politano VA, et al. Interposition flaps in trans-abdominal vesico-vaginal fistula repairs: are they really necessary? Urology 2001;57: 670-4.

3. Miller EA, Webster GD. Current management of vesico-vaginal fistulae. Curr Opin Urol 2001;11:417-21.

4. Roka ZG, Akech M, Wanzala P. Factors associated with obstetric fistulae occurrence among patients attending selected hospitals in Kenya, 2010: a case control study. BMC Pregnancy Childbirth 2013; 13:56.

5. Danso KA, Martey JO, Wall LL, Elkins TE. The epidemiology of genitourinary fistulae in Kumasi, Ghana, 1977-1992. Int Urogynecol J Pelvic Floor Dysfunct 1996;7:117-20.

6. Olusegun AK, Akinfolarin AC, Olabisi LM. A review of clinical pattern and outcome of vesico-vaginal fistula. J Natl Med Assoc 2009;101:593-5.

7. Goh JT. A new classification for female genital tract fistula. Aust N Z J Obstet Gynecol 2004;44:502-4.

8. Angioli R, Penalver M, Muzii L, et al. Guidelines of how to manage vesicovaginal fistula. Crit Rev Oncol Hematol 2003;48:295-304.

9. Sims JM. On the treatment of vesicovaginal fistula. Am J Med Sci 1852;23: 59-82.

10. Judith TW GOH. A new classification for female genital tract fistula. Austral New Zeal J Obstetric Gynaecol 2004;44:502-4.

11. Trendelenburg F. Discussion zu Helferich. Zuganglichmachung der vorderen Blasenwand. Verbandlung der Deutsche ges F Chir 1888;17:101.

12. Mackenrodt A. Die operative Heilung grosser Blasenscheidenfisteln. Zentralbl Gynakol 1894;8:180.

13. Blaivas JG, Heritz DM, Romanzi LI. Early versus late repair of vesico-vaginal fistulas: vaginal and abdominal approaches. J Urol 1995;153:1110-3.

14. Leach GE, Raz S. Vaginal flap technique: A method of trans-vaginal fistula repair. In: Raz S, ed. Female urology. Philadelphia: WB Saunders Co; 1983. pp 327. 
15. Raz S, Bregg KG, Nitti VW, Sussman E. Trans-vaginal repair of vesico-vaginal fistula using a peritoneal flap. J Urol 1993; 150:56-9.

16. Wang Y, Hadley RH. Non delayed trans-vaginal repair of high lying vesico-vaginal fistula. J Urol 1990;144:346.

17. Nezhat CH, Nezhat F, Nezhat C, Rottenberg H. Laparoscopic repair of a vesico-vaginal fistula: A case report. Obstet Gynecol 1994;83:899-901.

18. Nabi G, Hemal AK. Laparoscopic repair of vesico-vaginal fistula and right nephrectomy for nonfunctioning kidney in a single session. $J$ Endourol 2001;15:801-3.

19. Wall LL, Karshima JA, Kirschner C, Arrowsmith SD. The obstetric vesicovaginal fistula. characteristics of 899 patients from Jos. Nigeria Am J Obstet Gynecol 2004;190:1011-9.

20. Eilber KS, Kavaler E, Rodriguiz LV, et al. Ten year experience with trans-vaginal vesico-vaginal fistula repair using tissue interposition. J Urol 2003;169:
1033-6.

21. Raassen TJIP, Ngongo CJ, Mahendeka MM. Iatrogenic genitourinary fistula: an 18- year retrospective review of 805 injuries. Int Urogynecol J 2014;25:1699-706.

22. Waaldijk K. The immediate management of fresh obstetric fistulas. Am J Obstet Gynecol 2004;191:795-9.

23. Olusegun AK, Akinfolarin AC, Olabisi LM. A review of clinical pattern and outcome of vesico-vaginal fistula. J Natl Med Assoc 2009;101:593-5.

24. Hawkins L, Spitzer RF, ChristoffersenDeb A, et al. Characteristics and surgical successes of patients presenting for repair of Obstetric fistula in Western Kenya. Int $\mathrm{J}$ Gynecol Obstet 2013;120:178-82.

25. Krishna Reddy SV, Ahammad Basha Shaik, Srinivas K. Surgical training in percutaneous nephrolithotomy: the learning curve. Kidney Urol Res 2016:2:1-7.

26. Tiong HY, Shim T, Lee YM, Tan JK. Laparoscopic repair of vesico-vaginal fistula. Tan Int Urol Nephrol 2007;39:1085-90.

27. Chibber PJ, Shah HN, Jain P. Laparoscopic O'Conor's repair for vesico-vaginal and vesico-uterine fistulae. BJU Int 2005;96:183-6.

28. O'Conor VJ Jr. Review of experience with vesico-vaginal fistula repair. J Urol 1980;123:367-9.

29. Rizvi SJ, Gupta R, Patel S, et al. Modified laparoscopic abdominal vesico-vaginal fistula repair-"MiniO'Conor” vesicotomy. J Laparoendosc Adv Surg Tech 2010;20:13-5.

30. Melamud O, Elehel L, Turbow B, Shanberg A. Laparoscopic vesico-vaginal fistula repair with robotic reconstruction. Urol J 2005;65:163-6.

31. Hemal A, Wadwa P. Robotic repair of vesico-vaginal fistula. In: Robotics in genitourinary surgery. London, UK: Springer; 2011. pp 611-616. 